\title{
Apocatarsis 2666. Representaciones del mal y el apocalipsis social en la novela de Roberto Bolaño.
}

\author{
Apocatarsis 2666. Representations of Evil and the Social Apocalypse in Roberto Bolaño's \\ Novel.
}

\section{Ernesto Abundis Martínez}

Departamento de Romanística. Universidad de Hamburgo (ALEMANIA)

CE: abundismartinez ernesto@hotmail.com / OD ORCID: 0000-0003-4813-2400

Anna-Lena Glesinski

Departamento de Romanística. Universidad de Hamburgo (ALEMANIA)

CE: lena.glesinski@web.de / OD ORCID: 0000-0001-9772-968X

DOI: $10.32870 /$ sincronia.axxiv.n77.18a20

Esta obra está bajo una Licencia Creative Commons Atribución-NoComercial 4.0 Internacional

(c) $\mathrm{BY} \cdot \mathrm{NC}$

Recibido: 17/09/2019

Revisado: $14 / 10 / 2019$

Aprobado: 13/11/2019

\section{RESUMEN}

El siguiente trabajo pretende delinear la arquitectura del mal como epicentro de la compleja narrativa bolaniana. El mal está abstraído hasta llegar a representar la omnipresencia del mal histórico de la humanidad, los incidentes pequeños de la novela parecen estar desconectados el uno con el otro, pero bajo la superficie son síndromes del mismo fenómeno. La idea que subyace es la de encontrar la estructura dentro de las diferentes representaciones del mal en la novela y cómo a partir de estas se desarrolla la idea de un apocalipsis como una lectura de la esperanza de los tiempos en vez de un pesimismo social. Es un intento de descifrar la esperanza apocalíptica dentro de la estética del mal de 2666, además de entender la enfermedad del hombre moderno, cuya fascinación por el horror es el oasis donde se contempla. 
Palabras clave: Representaciones del mal. Vasos comunicantes. Estética del mal. Apocalipsis. Apocatarsis, 2666, Bolaño, Roberto.

\section{ABSTRACT}

The following work aims to delineate the architecture of evil as the epicenter of the complex Bolanian narrative. The evil is abstracted until it represents the omnipresence of the historical evil of humanity, the small incidents of the novel seem to be disconnected from each other, but beneath the surface are syndromes of the same phenomenon. The underlying idea is to find the structure within the different representations of evil in the novel and how from these the idea of an apocalypse develops as a reading of the hope of the times instead of a social pessimism. It is an attempt to decipher the apocalyptic hope within the aesthetics of the evil of 2666 , in addition to understanding the disease of modern man, whose fascination with horror is the oasis where it is contemplated.

Keywords: Representations of evil. Communicating vessels. Aesthetics of evil. Apocalypse. Apocatarsis, 2666, Bolaño, Roberto.

Ich bin der Geist, der stets verneint! Und das mit Recht, denn alles, was entsteht, ist wert, dass es zugrunde geht. Drum besser wär's, das nichts entstünde, Zerstörung, kurz das Böse nennt, mein eigentliches Element.

(Goethe, 2005, p. 39) $^{1}$

El hombre es por naturaleza malo, dijo el filósofo Immanuel Kant (1792). Al leer la novela póstuma del escritor chileno Roberto Bolaño, a primera vista se nos plantea una afirmación absoluta de la frase

\footnotetext{
${ }^{1}$ [Soy el espíritu que siempre niega, y con razón, pues todo cuanto tiene principio merece ser aniquilado, y por lo mismo, mejor fuera que nada viniese a la existencia. Así, pues, todo aquello que ustedes denominan pecado, destrucción, en una palabra: el Mal, es mi propio elemento.]
} 
kantiana. Y en la novela se despliegan como parvada de aves de mal agüero, sucesos violentos, uno tras otro, como sí el mal no conociera un límite, como si este solo se tratara de un rio que fluye permanentemente: Cuatro teóricos de literatura alemana inmersos en la búsqueda de un escritor alemán casi matan a un taxista pakistaní, un periodista estadounidense debe temer por su vida solo por haber investigado sobre los asesinatos de cientos de mujeres en el norte de México. Una de las cinco partes de la novela consiste en una cadena aparentemente infinita de reportes forenses de cadáveres violados y maltratados de mujeres jóvenes. Como si fuera poco, los policías responsables de la investigación sobre estos crímenes se pasan el tiempo contando ínfimos chistes misóginos. Así sube el espiral del mal dentro de la narrativa de 2666 hasta llegar a la incorporación del mal del siglo pasado, el Holocausto.

Todas las diferentes partes de la novela exhiben relatos y microrrelatos de atmósferas malignas Ilenas de violencia y muerte. Como caer a un abismo dentro de un abismo, así pero hasta el infinito, el mal que se abisma dentro del mal. La novela delinea la maldad humana en todos los niveles imaginables. Es decir, el mal es su propio elemento, el epicentro de la narrativa. Bolaño forma parte de una generación desencantada de Latinoamérica que vio caer a diferentes utopías políticas y sociales. Muchos intelectuales escribieron desde el exilio como única opción, porque algunos gobiernos posdictatoriales todavía estaban permeados por la corrupción y el crimen organizado. Nuestro mundo entero está sobrecargado del consumo y de las consecuencias del capitalismo. El hombre destruye el medioambiente, con ello su propio espacio vital y por ende, a sí mismo. Resulta evidente que de esas experiencias surge una narrativa pesimista en cuanto al futuro social del siglo $X X I$.

¿Pero valdría la pena dedicar sus últimos años en este mundo escribiendo una novela extensa de más de mil páginas con la única intención de lamentarse sobre el precipicio hacia donde se encamina la sociedad moderna? ¿Realmente se trata de una visión tan pesimista del fin del siglo XX en la que la civilización construyó sistemas burocráticos que en su complejidad e inteligencia artificial ya superaron a la competencia humana? 
La complejidad misma de la novela es el primer indicio en el viaje policiaco que empezamos los lectores de 2666. De tal manera que todos los episodios y relatos están unidos en la novela como una totalidad. Solo al contemplar las cinco partes (que el autor originalmente quería publicar como cinco novelas diferentes) nos damos cuentas como están relacionadas por detalles directos, metafóricos o simbólicos. Igual que en los vasos comunicantes que plantea Vargas Llosa en Cartas a un joven novelista, existe una comunicación recurrente entre los diferentes partes y relatos de la novela. Así que, como exige Vargas Llosa, la constitución de las partes sea siempre algo más que la mera suma de sus partes (1997, p. 143).

Este ensayo presenta algunas ideas iníciales en el análisis de la comunicación interparcial de la novela 2666 que ojalá puedan acercarnos al entendimiento de la estructura compleja de la estética bolaniana. En un primer intento se buscará encontrar la estructura de las diferentes representaciones del mal en la novela y después veremos cómo a partir de la maldad recurrente se desarrolla más bien una idea de apocalipsis en vez de un pesimismo social. Es un intento de descifrar la esperanza apocalíptica dentro de la estética del mal de 2666.

\section{Representaciones del Mal en 2666}

En un primer plano asociamos lo malo kantiano dentro de cada hombre con las manifestaciones, ya sea las violaciones de poder como la violencia física contra seres inferiores (más débiles). Lo impactante y más irritante en casi todas las representaciones del mal sigue siendo la supuesta perversión en el gozo secreto que provocan los actos violentos en el violador (verdugo). La violencia en 2666 se desarrolla en diferentes niveles. En la primera parte de la novela, se describe como cuatro críticos de literatura (Norton, Espinoza, Morini y Pelletier) de diferentes países de Europa (Inglaterra, España, Italia y Francia) viajan por el mundo en búsqueda de un escritor alemán.

El misterioso escritor se llama Benno von Archimboldi (Hans Reiter) y su vida parece un secreto bien guardado entre cambios de nombre, lugar e identidad. En una noche en Londres durante una discusión ingenua sobre la teoría literaria del laberinto de Jorge Luis Borges entre los críticos y un taxista paquistaní, esta termina en una pelea física, casi mortal para el taxista. Bajo el pretexto de 
restaurar la honra de su compañera y vengarse de las acciones misóginas del taxista, quien llama "puta" a Norton, Espinoza y Pelletier patean al hombre que para nada había esperado tal reacción violenta de esos hombres tan bien vestidos. Allí se figura la primera representación mefistofélica detrás de un vestuario intelectual. La muestra de poder hasta les provoca una sensación de goce sexual:

Cuando cesaron de patearlo permanecieron unos segundos sumidos en la quietud más extraña de sus vidas. Era como si, por fin, hubieran hecho el ménage a trois con el que tanto habían fantaseado. Pelletier se sentía como si hubiera corrido. Lo mismo, con algunas diferencias y matices, Espinoza. Norton, que los miraba sin verlos en medio de la oscuridad, parecía haber experimentado un orgasmo múltiple. (Bolaño, 2004, p. 103).

La cuarta parte de la novela "La parte de los crímenes" es la parte más larga y en 352 páginas se describe como 109 víctimas fueron asesinadas de manera semejante a un fenómeno factual ocurrido en el norte de México: el feminicidio. Durante los últimos 20 años fueron encontrados cientos de cadáveres violados y maltratados de mujeres jóvenes en su mayoría de origen rural, trabajadoras de las maquiladoras en las afueras de Ciudad Juárez, Chihuahua. Uno de los aspectos más devastadores de los asesinatos es la constante impunidad en la que se mueven los asesinos. No hay investigaciones verdaderas y los supuestos culpables que a veces son llevados a juicio, solo demuestran la existencia real de la tortura como método de construcción de declaraciones y la carencia de justicia dentro del sistema judicial del país ${ }^{2}$. La forma de presentar a las víctimas de feminicidio en 2666 nos recuerda al teatro de la crueldad de Antonin Artaud o una exhibición del horror. Se trata de la yuxtaposición de las descripciones de los cuerpos hallados, salpicados de episodios absurdos dentro de la búsqueda de culpables que nada más evidencian la incapacidad de las autoridades, la ignorancia de la sociedad civil y la infiltración de la corrupción dentro del sistema administrativo judicial. Existen casos en los

\footnotetext{
2 El libro El feminicidio de Ciudad Juárez. Repercusiones legales y culturales de la impunidad del año 2012 coordinado por Salvador Bernabéu Albert y Carmen Mena García es un conjunto de ensayos sobre los aspectos políticos, históricos y sociales del caso de las así llamadas muertas de Juárez. Algunos capítulos están dedicados a la transposición del tema a la escena artística (literatura, arte plástica, teatro).
} 
cuales se demuestran que los asesinos ni siquiera ven la necesidad de ocultar bien a las muertas ni disimular el grado de perversión de los acontecimientos:

El cuerpo, que hallaron semioculto detrás de unas cajas de cartón. Estaba desnudo de cintura para abajo. Las piernas estaban manchadas de sangre. Tanta sangre que vista de lejos, o vista desde una cierta altura, un desconocido (o un ángel, puesto que allí no había ningún edificio desde el cual contemplarla) hubiera dicho que llevaba medias rojas. La vagina estaba desgarrada. La vulva y las ingles presentaban señales claras de mordidas y desgarraduras, como si un perro callejero se la hubiera intentado comer. Los judiciales centraron las investigaciones en el círculo familiar [...]. (Bolaño, 2004, p. 577).

La acusación inherente que leemos en este pasaje es que allí ya desde hace mucho pasó el 1 de marzo de las 120 jornadas de Sodoma y la conclusión a la que podemos llegares que no existe ninguna posibilidad de detener la derrota moral de la sociedad. Como caso ejemplar de la imparable contaminación de lo perverso siguen réplicas del pesimismo cultural del fin de siglo XX al siglo XXI.

La estrangulación de un nazi, que acaba de admitir su culpa en la muerte de varios judíos seguramente estremece los ideales éticos de muchos de nosotros. Hans Reiter tomó justicia por propia mano, porque supo que nunca se iba a castigar al nazi Sammer que había matado a cientos de judíos. Todos entendemos la ira que trastoca a Hans Reiter, ¿̇pero es esto una justificación para tomar la justicia por sus propias manos, le da una licencia para matar? La sensación de justicia o injusticia en lo referente a las víctimas juega un papel decisivo en la acumulación de la violencia, porque en nuestra percepción moral, marcada por influencias culturales, la violencia por motivos de venganza desciende de forma gradual el nivel de compasión con la víctima. Más inocente la víctima, más compasión provoca la acción violenta contra la persona. En la introducción hablamos de un espiral del mal que se puede especificar en una escalada que sube sin frontera alguna por la gravedad de los actos de violencia injustificada.

En los primeros años los asesinatos de las mujeres inocentes no provocaron indignación en la sociedad civil. Seguramente tiene que ver con el estatus subalterno de las mujeres rurales, 
marginadas de un sistema que las vuelve invisibles. No había gritos estridentes que pudieran ser escuchados por la sociedad. Estas víctimas y sus familias no tuvieron ninguna voz para articular su dolor delante de la sociedad civil. Solo ahora que el síndrome juarense tiene un nombre propio (el feminicidio) y diversos personajes de la vida pública tratan el tema, se escucha un eco, aunque todavía demasiado bajo por las esquinas de la vida social.

El epígrafe de Baudelaire "Un oasis de horror en medio de un desierto de aburrimiento", utilizado por Bolaño (2004) y con el cual se abre la novela, ya alude a que la ciudad en el desierto, locación de Santa Teresa - igual que su contraparte real Ciudad Juárez - está en el centro de todo. Teniendo en cuenta que la cita está sacada del poema El Viaje que trata la muerte y el viaje que nos lleva o al cielo o al infierno, el lector tiene que prepararse para una narración que va descendiendo. Hacia abajo en dirección al fin de la vida y el horror se instala a un costado como compañero de viaje. Según el teórico francés, Jean Baudrillard, la inteligencia del mal se manifiesta en cada uno de nosotros. La enfermedad del hombre moderno, cuya fascinación por el horror es el oasis donde se contempla en los días.

Lo malo es la entidad que nos piensa a nosotros y no al revés. Lo malo está automáticamente dentro de la actuación humana (2006, p. 140). Es la idea de las dos caras de la medalla que niega una existencia singular. Lo bueno y lo malo están inseparablemente conectados. Baudrillard explica detalladamente como el hombre teme la responsabilidad y que el sistema político es el signo que el miedo humano tiene de sí mismo y su propia falacia. De acuerdo con el autor, hasta los políticos mismos temen la responsabilidad de su poder y se deshacen del valor simbólico que lleva el poder (2006, p. 146-147). Además plantea que construyendo un sistema político, una sociedad distribuye el mal (2006, p. 149) porque distribuye las responsabilidades.

Roberto Bolaño demuestra en la cuarta parte de su novela como la distribución excesiva de responsabilidades como no solo lo vemos en Santa Teresa sino en todas las sociedades que basan sus políticas en un fondo burocrático, la responsabilidad se pierde completamente. Construyendo un sistema en el cual se distribuye el mal en una serie de responsabilidades pequeñas, la gravedad de cada falacia administrativa y simultáneamente aumenta el grado de malicia en conjunto. 
Especialmente en ámbitos políticos débiles, donde existen corrupción e inestabilidad democrática, florece la irresponsabilidad de los miembros. El sistema judicial de la ciudad ficticia Santa Teresa encarna la administración del mal en el sentido baudrillardano. Según él, el fracaso secreto de la política es que el mal ya no se piensa, sino existe y crece por las manifestaciones colectivas y está distribuido en todas las almas diferentes del sistema:

Es ist das geheime Scheitern der Politik, nicht mehr dazu in der Lage zu sein das Böse zu denken. Das Politische ist der Ort der Ausübung des Bösen, der Verwaltung des Bösen, verstreut in den individuellen Seelen und kollektiven Manifestationen in all ihren Formen - in der Form des Privilegs, der Sünde, der Korruption. Die Fatalität der Macht besteht darin, diesen verfemten Teil auf sich zu nehmen, und die der Machthaber, diesem geopfert zu werden - ein Privileg, von dem sie sich jeglichen sekundären Nutzen erwarten. Das Böse auszuüben ist jedoch schwierig; man kann davon ausgehen, dass sie permanent versuchen, sich seiner auf alle möglichen Arten zu entledigen. (Baudrillard, 2006, p. 145). ${ }^{3}$

¿Y qué hay acerca de tu religión? Le pregunta la joven Gretchen al doctor Fausto, así como por la esencia real de sus intenciones e ideales. Es la misma exigencia que nos hace Bolaño cuando nos hace la descripción de las mujeres asesinadas. Sus decisiones discursivas en 2666 confrontan a los lectores directamente con los crímenes de Santa Teresa y como no se resuelven nunca, se activa la curiosidad policial y el sentido de responsabilidad de los lectores. Como diría Baudrillard (2006, p. 148) ¿Qué pasa si les quitamos la máscara a los políticos para ver nuestra propia responsabilidad dentro de la culpa colectiva que surgió por sentimientos de resignación o letargo? ¿Nos liberamos, o morimos de miedo ante la presencia del mal delante de nuestros ojos?

“¿Qué hace el niño cuando tiene miedo? Cerrar los ojos. ¿Qué hace un niño al que van a violar y luego matar? Cierra los ojos. Las palabras servían para ese fin” (Bolaño, 2004, p. 338). Esta cita que

\footnotetext{
${ }^{3}$ [Es el fracaso secreto de la política el no poder pensar el mal. Lo político es el lugar de la práctica del mal, la administración del mal, disperso en almas individuales y manifestaciones colectivas en todas sus formas, en forma de privilegio, pecado, corrupción. La fatalidad del poder es asumir esta parte proscrita, y las de los gobernantes, para ser sacrificadas a ella, un privilegio del que esperan todos los beneficios secundarios. Sin embargo, practicar el mal es difícil; se puede suponer que constantemente intentan deshacerse de él de todas las formas posibles.]
} 
se dice dentro de una conversación en un restaurante en Tucson por el Dr. Kessler se convierte en un tema central de la novela. Es la naturaleza humana cerrar los ojos en situaciones de violencia. Transmitido de un niño pequeño con miedo, a la sociedad entera, significa que no tiene la fuerza de oponerse al enemigo. La sociedad se incapacitó a si misma cuando distribuyó las responsabilidades y ahora parece un niño pequeño delante de un violador omnipotente e invencible.

El crimen de Santa Teresa llegó a un nivel fuera de control y la sociedad entera se convierte en un niño que cierra los ojos delante de la omnipotencia y omnipresencia del mal, la cual surgió en medio de sí misma. Nadie sabe quiénes exactamente son los asesinos ni quiénes encubren a los culpables. Si una persona dentro del sistema corrupto intenta cambiar la situación, pronto se da cuenta de que se liberó a un monstruo invencible e incontrolable. Lo que desde afuera parece indiferencia es más bien un letargo colectivo nacido de la resignación de los individuos. Esta actitud se refleja en la atmósfera del libro. Los críticos en realidad no esperan encontrar nunca a Archimboldi, sus esfuerzos son más bien intentos de preservar el contacto interpersonal entre sí. La repetición de los casos de asesinatos de forma tan fría y la indiferencia de la sociedad mexicana, sustentan la teoría de que se resignaron en la lucha contra la violencia. Pues está ya forma parte natural de la vida diaria. Rojas Torres y López de Adiada (2012) lo comparan con una enfermedad contagiosa, pero en realidad es aún peor, porque dicha enfermedad siempre estaba dentro de las personas y la sociedad nunca va a lograr curarse o librarse de ella. No es una excrecencia innatural, sino una parte intrínseca del cuerpo humano. Cada época tiene su propia incorporación del mal, sea como diablo o como catástrofe. El mal está dentro de cada uno de nosotros y bajo ciertas circunstancias siempre emerge.

Como ya hemos mencionado antes, la densidad del mal en 2666 alcanza un nivel extremo. Encontramos las múltiples caras de la muerte: causada por enfermedades (Madre de Fate, Ingeborg), violencia física (los críticos), violencia estructural (detenciones por parte de dirigentes soviets), ejecuciones (el escritor Ivánov): “No volvió a su celda. Lo sacaron directamente a un patio, alguien le pegó un tiro en la nuca y luego metieron su cadáver en la parte de atrás de un camión" (Bolaño, 2004, p. 910). La maldad de la perversión como en las películas snuff, en el caso de las muertas de Santa Teresa o la tortura de contrincantes políticos como Entrezcu. Enumerar todas las representaciones 
del mal dentro de la novela queda fuera de los límites de este ensayo, pero con los ejemplos hemos dado una idea de lo delineado en los relatos y microrrelatos.

La referencia al nacionalsocialismo representa la culminación de la serie del mal dentro de la novela, porque en el entendimiento moderno es la incorporación del mal en el siglo XX. En el quinto capítulo se describe, entre otros, como el alemán Leo Sammer le cuenta a Hans Reiter que mató a 400 judíos en Polonia. Pero siempre encontró la manera de disminuir la responsabilidad de su papel dentro del asesinato. Él estaba estacionado en un pueblo en Polonia y recibió la noticia que le iban a mandar 500 judíos griegos. No se sabe exactamente cuál era el destino original del tren. La orden de "deshacerse de ellos" llegó por teléfono. Sammer cuenta que les organizó pan y mantas, aseverando que no era su culpa que no hubiera comida para todos. Las palabras del nazi Leo Sammer nos traen al recuerdo las de Adolf Eichmann, un nazi alemán que fue condenado en un juicio en Jerusalén por haber asesinado a cientos de judíos en la época del nacionalsocialismo. Siempre insistía en que solo siguió órdenes y que hizo todo lo posible para hacer más llevadera la vida de los judíos. Sammer insiste en su carácter decente para liberarse de cualquier tipo de culpa, añadiendo comentarios como: "He sido demasiado bueno con esa gente [los campesinos polacos], me decía mentalmente a mí mismo, ya va siendo hora de mostrarme duro. La dureza, sin embargo, va reñida con mi carácter" (Bolaño, 2004, p. 951).

¿Para qué sirve la comparación del personaje ficticio Leo Sammer y el asesino factual Adolf Eichmann? En 1961 Eichmann se defendió delante de una corte en Jerusalén y la filósofa alemana Hannah Arendt documentó sus declaraciones en su libro Eichmann en Jerusalén. Fue demasiado difícil comprobar la culpa de Eichmann, porque había actuado dentro de un sistema burocrático complejo. Un sistema que ya había superado a los hombres que lo manejaban. La mayoría de los culpables de la muerte de 6 millones de judíos fueron pequeños engranajes dentro de una gran máquina del mal:

Daß es im Wesen des totalen Herrschaftsapparates und vielleicht in der Natur jeder Bürokratie liegt, aus Menschen Funktionäre und bloße Räder im Verwaltungsbetrieb zu machen und sie damit zu entmenschlichen, ist von Bedeutung für die Politik- und Sozialwissenschaften, und 
über die Herrschaft des Niemand, die eigentliche Staatsform der Büro-kratie, kann man sich lange und mit Gewinn streiten.(Arendt 2011, p. 59). ${ }^{4}$

Dentro de esa máquina existen personas que se liberan hasta de la más mínima responsabilidad, aunque desde sus escritorios hayan organizado cientos de asesinatos. En alemán se les llama Schreibtischtäter (autores morales). Está expresión tiene como fondo los textos de Hannah Arendt. Aunque en realidad ninguna de las maldades se puede comparar con la maquinaria del nacionalsocialismo, tenemos que tomar en cuenta que Bolaño las confronta en su novela. Al fin y al cabo todos los relatos demuestran como los humanos jugamos con la noción de responsabilidad y conciencia cada vez que entramos dentro de una identidad colectiva social. El anhelo de formar parte de un grupo ya establecido parece valorarse más dentro de la percepción humana que la razón misma.

Mein Bericht hat sich bei diesem Kapitel aufgehalten, das der Jerusalemer Prozeß der Welt nicht in seinem wahren Ausmaß vor Augen führte, weil es den tiefsten Einblick in die Totalität des moralischen Zusammenbruchs gewährt, den die Nazis in allen, vor allem auch in den höheren Schichten der Gesellschaft ganz Europas verursacht haben - nicht allein in Deutschland, sondern in fast allen Ländern, nicht allein unter den Verfolgern, sondern auch unter den Verfolgten. (Arendt, 2011, p. 219). ${ }^{5}$

Arendt describe que la Herrschaft des Niemand (regencia de nadie) es la idea, de que en un sistema burocrático no reina nadie, sino es el sistema mismo el que se mantiene. Así nadie toma responsabilidades sobre los crímenes que se cometen dentro de este sistema. En todos los actos

\footnotetext{
${ }^{4}$ [Es importante para las ciencias políticas y sociales, y para el gobierno de Nadie, que la naturaleza del aparato total del poder, y tal vez la naturaleza de toda burocracia, sea hacer que las personas sean funcionarios y meras ruedas en la empresa administrativa, y deshumanizarlos, forma actual del estado de la Büro-kratie (oficina-kratie), se puede discutir durante mucho tiempo y con fines de lucro.]

${ }^{5}$ [Mi informe ha sido en este capítulo, que el proceso mundial de Jerusalén no se ha demostrado en su verdadero alcance, ya que proporciona la visión más profunda de la totalidad del colapso moral que los nazis tienen en todos, y especialmente en las clases más altas, causado no solo en Alemania, sino en casi todos los países, no solo entre los perseguidores, sino también entre los perseguidos.]
} 
violentos que plantea la novela, estamos confrontados con la pérdida de conciencia de la responsabilidad dentro de un grupo. Lo que llamamos el mal está incorporado dentro del hueco que la burocracia ha abierto dentro de la sociedad. El metafórico ménage a trois entre los tres críticos en la primera parte muestra que hasta Norton que en un momento quiso terminar la pelea entre los hombres y el taxista experimenta una especie de satisfacción sexual solo porque formaba parte del grupo de agresores.

Para agudizar la idea la comparamos con el teorema de Gleichschaltung (Arendt, 2011, p. 218) que en principio inventaron los nazis pero que bajo la especificación de una sincronización voluntaria como también Hannah Arendt lo llama, se describe este anhelo intrínseco del hombre de formar parte de un grupo y olvidar sus propios ideales para no pertenecer a los excluidos, a los marginados. Es decir, en adición a la presencia visible del mal dentro de la novela representada por crímenes violentos contra seres inocentes vemos un mal creado por el hombre como entidad colectiva y existe otra representación aún menos visible.

Im Dritten Reich hatte das Böse die Eigenschaft verloren, an der die meisten Menschen es erkennen - es trat nicht mehr als Versuchung an den Menschen heran. Viele Deutsche und viele Nazis, wahrscheinlich die meisten, haben wohl die Versuchung gekannt, nicht zu morden., nicht zu rauben, ihre Nachbarn nicht in den Untergang ziehen zu lassen (denn daß die Abtransportierung der Juden den Tod bedeutete, wussten sie natürlich, mögen auch viele die grauenhaften Einzelheiten nicht gekannt haben) und nicht, indem sie Vorteile davon hatten, weiß Gott, gelernt, mit ihren Neigungen fertigzuwerden und der Versuchung zu widerstehen. (Arendt, 2011, p. 249). ${ }^{6}$

Esta cita de Hannah Arendt demuestra como el horror se normalizó en la época del nacionalsocialismo en Alemania. Es como si la sociedad hubiera estado acostumbrada desde siempre

\footnotetext{
${ }^{6}$ [En el Tercer Reich, el mal había perdido el rasgo que la mayoría de la gente reconoce: ya no era una tentación para los humanos. Muchos alemanes y muchos nazis, la mayoría de ellos, probablemente conocían la tentación de no matar. No querían robarles, no querían que sus vecinos perecieran (porque, por supuesto, sabían que los judíos estaban siendo transportados lejos) muchos no sabían los detalles horripilantes) y no, habiéndose beneficiado de ello, solo Dios sabe, aprendieron a sobrellevar sus inclinaciones y resistir la tentación.]
} 
al grado de violencia que cometieron los nazis. La filósofa fue criticada en ocasiones por su opinión radical en cuanto a la culpa concerniente a la sociedad civil. Pero según ella, el mal había perdido su característica esencial en el nacionalsocialismo - la tentación. Arendt comenta que la situación incluso cambió hasta el otro extremo, ya que los alemanes sintieron cierto grado de tentación para no matar, no robar, etcétera. Partiendo de esa teoría comparamos la idea de 2666 que algunos contextos sociales tergiversan la percepción del mal hasta el extremo contrario, hasta su normalización.

En la quinta parte, La Parte de Archimboldi, todas las historias y las relaciones entre las diferentes partes se develan, en cierto modo la última parte da sentido a las demás. Este hecho se manifiesta en el nombre que elige Hans Reiter para su nueva identidad: Archimboldi. Este nombre nos recuerda al artista manierista, Guiseppe Arcimboldo (a veces Archimboldi, 1527-1593) quien pintaba retratos de personas construidas a partir de un collage de plantas, animales u objetos. Colocaba los objetos de tal manera que todo el conjunto formaba el rostro. Bolaño pinta un retrato del mal pars pro toto igual que Arcimboldo. Los incidentes pequeños de la novela en un primer plano no tienen nada que ver el uno con el otro, pero bajo la superficie son síndromes del mismo fenómeno. Sonja Stajnfeld declara como en el discurso bolaniano el mal está abstraído hasta llegar a representar la omnipresencia del mal histórico de la humanidad:

Con estos procedimientos se disminuye el aspecto individual del mal, tanto del lado de las víctimas como del de los verdugos, para resaltarlo, extraerlo y, así, enfatizarlo como una abstracción presente a lo largo y ancho de la historia de la humanidad. Al volver borrosos los contornos individuales de los perversos, se consigue el efecto de un mal abstraído de los contextos históricos para convertirlo en algo omnipresente. (Staijnfeld, 2012, p. 81).

\section{Comunicación interna y vasos comunicantes}

Desde el lugar omnipresente que toma el mal en la escena discursiva, podemos seguir hablando sobre la interconectividad de las partes de la novela. De cierta manera todos los relatos se conectan por la omnipresencia del mal, este es el sendero que los liga en la novela. Más abajo vamos a retomar ese 
canal y volver a la teoría literaria de Mario Vargas Llosa. La novela 2666 no solo presenta conexiones internas, sino también se refiere a otras obras del autor mismo, estructuras fractales. Por ejemplo encontramos un cementerio olvidado del año 2666 en la novela Amuleto y la descripción se incorpora en la alegoría bolaniana de cerrar los ojos delante del mal: "[...] a un cementerio del año 2666, un cementerio olvidado debajo de un párpado muerto y nonato, las acuosidades desapasionadas de un ojo que por querer olvidar algo ha terminado por olvidarlo todo" (Bolaño, 1999, p. 77).

Además el personaje Amalfitano aparece tanto en 2666 como en un cuento llamado "otro cuento ruso" en Llamadas telefónicas (1997). En Los detectives salvajes (1998) existe la referencia a un tal año 2600 y pico. Como diría Ulrich Suerbaum en su definición de intertextualidad: “Genre begins at home", (1985, p. 68) podemos afirmar que la obra compleja que dejó el escritor a los 50 años parece una sola obra intertextual y fractal. Arriesgándonos a hablar de un género bolaniano que se completó con una de sus últimas novelas.

Un hecho interesante en cuanto al nombre de la ciudad ficticia Santa Teresa es que no sólo es un barrio real en Ciudad Juárez, sino que el nombre del barrio existe en un sin número de ciudades mexicanas y también en algunas partes del mundo (p.e. barrio de Río de Janeiro, Guadalajara, una ciudad en Italia, etcétera). Se nos inserta de forma inconsciente la idea de que el síndrome santateresiano es un síndrome mundial. La internacionalidad se refleja en todas partes dentro de la novela. Los críticos vienen de países diferentes de Europa, Amalfitano es chileno, Archimboldi un alemán que cambia su nombre a un nombre italiano, Fate es estadounidense, hay diversos personajes rusos y rumanos, personajes coetáneos en una aldea global. No es por nada que las recensiones pertinentes lo llaman literatura universal.

Otra interconexión de los diferentes relatos dentro de la novela se desarrolla en las recurrentes representaciones del mal, esta sería la enfermedad de Ingeborg, esposa de Archimboldi, acercándonos del nivel social al nivel mitológico. Ella murió de forma cruel de tuberculosis y nadie la podía ayudar. Las conexiones asociativas dentro de la trama de la novela se vuelven complejas con cada nuevo relato. El cuerpo enfermo de la mujer se muestra también en la muerte de la madre de Fate, el periodista estadounidense, en la muerte de la esposa de Archimboldi y como Bieke Willem 
hace resaltar, se usa la metáfora de la enfermedad para reflejar las infamias que están pasando en Santa Teresa: "Por la metáfora de la ciudad como cuerpo enfermo y caníbal (el cielo, al atardecer, parecía una flor carnívora (2004, p. 172), Santa Teresa parece reflejar todas las infamias que tienen lugar en ella" (Willem, 2013, p. 81).

Teniendo la novela en cuenta como un conjunto, se entiende que en todo el mundo existe y siempre ha existido el mal. La violencia pertenece al comportamiento humano como las enfermedades. Así afirman también Rojas Toro y López de Abiada (2012) en su artículo sobre el feminicidio en Bolaño: "La convicción de que el Mal es concomitante a la naturaleza humana anima a Bolaño escritor a limitarse en su descripción. La muerte se ha instalado y se pavonea en Santa Teresa como una enfermedad contagiosa" (2012, p. 194).

Como al principio ya planteamos, el escritor peruano, Mario Vargas Llosa presentó una definición sobre la comunicación entre las partes diferentes dentro de un texto complejo:

Dos o más episodios qué ocurren en tiempos, espacios o niveles de realidad distintos, unidos en una totalidad narrativa por decisión del narrador a fin de que esa vecindad o mezcla los modifique recíprocamente, añadiendo a cada uno de ellos una significación, atmósfera, simbolismo, etcétera, distinto del que tendrían narrados por separado. La mera yuxtaposición no es suficiente, claro está, para que el procedimiento funcione. Lo decisivo es que haya "comunicación" entre los episodios acercados o fundidos por el narrador en el texto narrativo. (1997, p. 143).

Los relatos de 2666 se comunican en varios niveles. Primero tenemos la omnipresencia del mal en casi todos los relatos. Si no se vieran todos como un conjunto, el lector se enfocaría en otras partes. Existen conexiones interpersonales en las cinco partes de la novela y otras obras del autor. Al fin de cuentas, todos y cada uno de los protagonistas de los cinco libros de 2666 llegan a Santa Teresa, excepto Morini pero quien es el primero de los cuatro críticos que tiene la visión del infierno santateresiano. La noticia más reciente sobre Benno von Archimboldi, fue precisamente dirigiéndose allí, los tres críticos de la primera parte siguen a este mismo escritor misterioso, Amalfitano vino por 
un puesto en la universidad, y las muertas del feminicidio de la cuarta parte se encuentran en la ciudad del desierto.

En su complejidad la novela sigue construyendo un sistema de acción-reacción que refleja el modelo antes mencionado de los vasos comunicantes. Por un lado encontramos conexiones directas. Los críticos se van a Santa Teresa, porque Archimboldi siguió a su hermana que a su vez dejó su país, porque su país fue derrotado físicamente y emocionalmente después de la guerra. Además se encuentran hilos de asociación que solo en conjunto revelan los excesos humanos en cuanto al poder y la violencia. Si solo vemos una calabaza y un par de uvas, no se sabe de inmediato que estos elementos pueden servir a un pintor italiano para formar la cabeza de Rudolf II. ¿Pero a qué fin Ileva la comunicación? ¿Se van a desbordar los vasos comunicantes o van a secarse en el desierto discursivo de la estética bolaniana? Hay que averiguar si el autor realmente nos enfrenta con unas réplicas de un pesimismo de fin du siècle o si contiene una exigencia.

El mal que en el folclore europeo muchas veces está representado por el diablo, Mefistófeles, se incorpora en todos los actos de crueldad y violencia que aterrorizan la realidad de los individuos y de la sociedad en conjunto. En la cultura urbana de los últimos 30 años el signo más representativo del mal es el pentagrama invertido (Drudenfuß) y en centros urbanos y cultos satánicos el número 666 es el número del diablo. En el apocalipsis de San Juan, último libro del Nuevo Testamento, se presentan dos monstruos de los que uno tenía cuernos, pero hablaba como un dragón. Este mismo, el anticristo en persona, hizo caer el fuego del cielo sobre la tierra y tuvo la fuerza de matar a todos los que no adoraran a la vida. Se dice que el monstruo tuvo un número: “Aquí hay sabiduría. El que tiene entendimiento, cuente el número de la bestia, pues es número de hombre. Y su número es seiscientos sesenta y seis" (Ap. 13:18, Reina-Valera, 1960). La decisión de usar este mismo número 666 en combinación con la referencia a una fecha en el futuro como título de la novela es una alusión fuerte al último libro del nuevo testamento: el apocalipsis. 


\section{Los cuatro jinetes del apocalipsis}

Esta parte que es la más simbólica de toda la biblia llamada "Apocalipsis" o "Revelaciones de San Juan" se anuncia el fin catastrófico de la historia o la humanidad tal como la conocemos y la llegada del reino de $\operatorname{Dios}^{7}$. Se usan sinónimos como fin de los tiempos, juicio final o fin del mundo. El género apocalíptico se refiere tanto a las revelaciones de San Juan como a textos religiosos del judaísmo o antiguos que tienen como objetivo la revelación de los secretos de Dios. Lo importante es que después del fin del mundo histórico empezarán nuevos tiempos llenos de gracia. La llegada del anticristo y la caída de estrellas del cielo solo son algunos signos de la llegada del último juicio.

El número del diablo en el título no es la única referencia apocalíptica en la novela. No es casualidad que Archimboldi y su esposa se instalan en la ciudad llamada Crimea. Por un lado contiene la palabra crime y por otro lado incluye uno de los primeros signos antes del desastre mundial (apocalipsis) que acabamos de implantar. En 1929 un asteroide cayó en la ciudad ucraniana. En el apocalipsis de San Juan se describe como antes del fin del mundo empezaron a caer meteoritos: "y las estrellas del cielo cayeron sobre la tierra, como la higuera deja caer sus higos cuando es sacudida por un fuerte viento" (Ap. 6:13, Reina-Valera, 1960).

A lo largo de la novela se refuerza la lluvia de crímenes que culmina en la enumeración de mujeres muertas. Parece una lluvia de meteoritos que ensangrienta sucesivamente al mundo humano y al leerlo, una amargura deprimente se instala en nuestra percepción. La violencia diaria que se presenta en 2666 es como una descripción de las últimas calamidades del apocalipsis. El tono

\footnotetext{
${ }^{7}$ Compárese Ediciones RIALP 1981, p.p. 463-472; Argumento del apocalipsis de San Juan sacado de la Gran Enciclopedia Rialp: "El A. Se presenta como un libro profético (Apc 1,3.19) que, por medio de vaticinios e imágenes, describe los hechos presentes y futuros de la Iglesia. La revelación va dirigida a Juan, el cual recibe el encargo de comunicarla a siete Iglesias de la provincia proconsular de Asia: Éfeso, Esmirnna, Pérgamo, Tiatira, Sardes, Filadelfia y Laodicea. Estas siete Iglesias representan a todas las cristiandades del Asia Menor a las cuales va dirigido el mensaje. El autor sagrado presenta al poder pagano de su tiempo luchando contra Cristo y su Iglesia. Ésta, aunque siempre perseguida, alcanzará finalmente la victoria total sobre sus enemigos. La lucha descrita por el A. Se refiere inmediatamente a la batalla librada por la Iglesia con los poderes paganos a finales del s. I, pero tiene un valor y un significado permanente, ya que la Iglesia en la tierra es esencialmente militante. Continuamente tiene y tendrá que hacer frente a las persecuciones y errores que irán apareciendo a través de los siglos. El A. Presenta la historia de la salvación bajo la imagen de una liturgia celeste, en la cual, por virtud del sacrificio del Cordero, se logra vencer el mal y las almas son incorporadas al Reino de Dios (v.). Por eso se alude continuamente a Cristo como pontífice celeste y a su sacrificio".
} 
principal de la novela es amargo y la gente está abrumada como el pueblo bíblico frente a las calamidades (plagas). Las señales siniestras que anuncian el apocalipsis son claras y para complementarlas incluso existe una Revelación sobrenatural cuando Florita, una mujer de 70 años, nombrada la Santa, tiene una visión acerca de los asesinatos de Santa Teresa:

Cerró los ojos. Abrió la boca. Su lengua empezó a trabajar. Repitió lo que ya había dicho: un desierto muy grande, una ciudad muy grande, en el norte del estado, niñas asesinadas, mujeres asesinadas. ¿Qué ciudad es ésa?, se preguntó. A ver, ¿qué ciudad es ésa? Yo quiero saber cómo se llama esa ciudad del demonio. (Bolaño 2004, p. 546).

Además dentro de la novela encontramos a un personaje que se llama Juan de Dios Martínez, quien es un judicial asignado a la investigación en el caso de las mujeres asesinadas. El hombre pierde la esperanza, porque la gente y las circunstancias evitan que se resuelvan los casos. Por ejemplo le da gripe y en consecuencia se pierde la posibilidad de verificar pruebas forenses. Se pierden las pruebas del semen que mandó a Hermosillo, etc. Juan de Dios Martínez también estaba involucrado en el caso de Klaus Haas, sobrino de Archimboldi, quien es el presunto asesino serial de la historia. En la última parte, el escritor ruso Ivanov se encuentra en la Casa del Escritor con los cuatro críticos y menciona que cenó “con cuatro amigos que parecían los cuatro jinetes del apocalipsis" (Bolaño, 2004, p. 890).

En la quinta parte de la novela, que se titula "La parte de Archimboldi", se develan las últimas relaciones entre los diferentes relatos centrales. Los relatos se agrupan en forma de estrella o pentagrama y Santa Teresa forma el centro. El siguiente modelo explica las relaciones: 


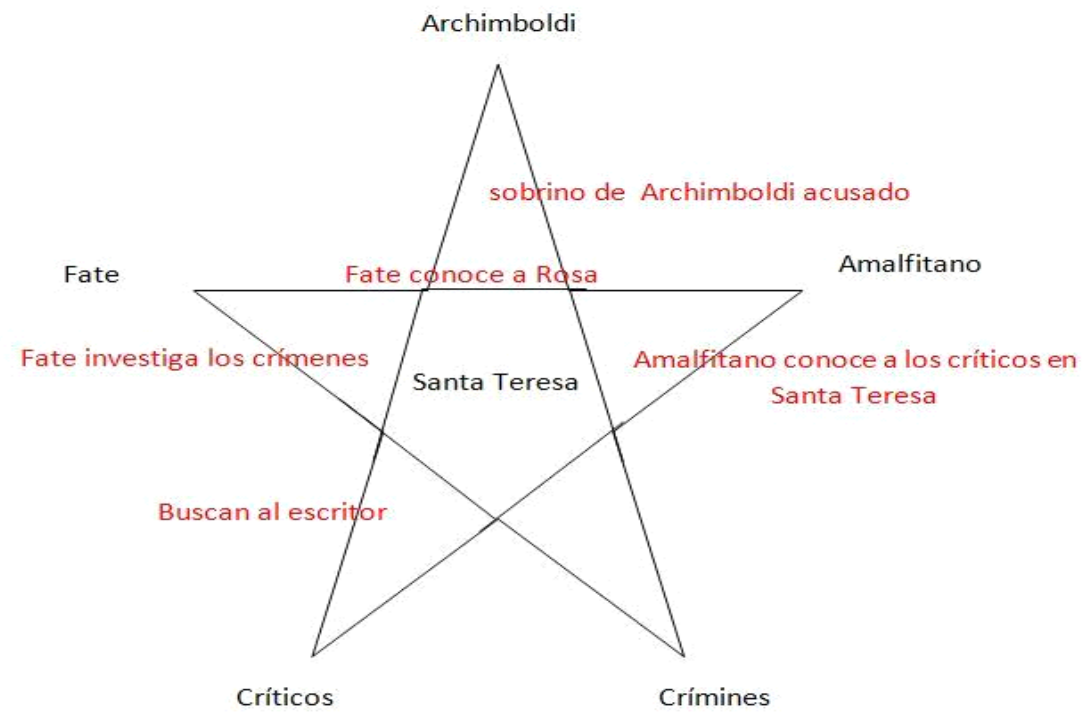

Fuente: Creación propia

Los críticos (parte I) conocen a Amalfitano (parte II) cuya hija Rosa investiga con Fate (parte III). El escribe sobre los crímenes de Santa Teresa (parte IV) y el acusado de los crímenes fue el sobrino de Archimboldi (parte V). Y para terminar de construir el pentagrama, Archimboldi es buscado por los críticos. La ciudad Santa Teresa está en el centro de todos los relatos. El pentagrama se pinta sin despegar el lápiz construyendo el orden de las cinco partes. Desde la Edad Media el pentagrama se usa para apartar el mal. Recordamos que en el Fausto de Goethe el Mefistófeles que citamos al principio de este ensayo no pudo salir del cuarto de Fausto, porque había un pentagrama en la puerta.

La estructura de la novela ya alude que la visión que da el número 666 en el título no es solo un presentimiento amenazador. Primero pensamos en los cultos satánicos que convirtieron el pentagrama invertido en un símbolo de Satán, después vemos las culturas roqueras y heavy metal que lo hicieron presentable en la sociedad civil. Aquí como en otras ocasiones, Bolaño juega con las asociaciones individuales de los recipientes. La palabra griega apocalipsis significa la revelación de que, a pesar del aparente triunfo del mal, la victoria final y decisiva sería de Dios. Aún en el siglo XXI el cristianismo se extiende por el mundo entero y las alegorías apocalípticas se entienden o se 
conocen a nivel mundial. En el último capítulo del nuevo testamento San Juan describe en metáforas y símbolos las previsiones del futuro apocalipsis (Reina-Valera, 1960). Se trata del fin del mundo como lo conocemos y la llegada del reino de Dios. Claro está que los símbolos cristianos que usa Bolaño en 2666 forman parte de una alegoría compleja que aún significa más en la realidad latinoamericana que en la europea.

La continua apariencia del mal en el mundo humano y la aparente indiferencia de una sociedad paralizada llevarán al fin del mundo. Sumando todos los indicios, el apocalipsis bolaniano es inevitable y al parecer no hay remedio. Incluso llegaron los emisarios de San Juan. En el sexto capítulo de las Revelaciones Ilegan los Cuatro Jinetes como precursores del apocalipsis cercano. La pintura de Viktor Vasnetsov Cuatro jinetes del apocalipsis (1887) muestra a los jinetes como salieron del libro cuando el Cordero rompió uno tras otro los sellos del libro de los siete sellos.

Al principio de la novela 2666 llegan cuatro emisarios que difunden la teoría de una leyenda. Uno de ellos menos fuerte que los demás. Liz Norton, Jean-Claude Pelletier, Manuel Espinoza y Piero Morini, cuatro críticos de literatura cuya vida académica y privada está rodeada por la obra de un escritor ominoso alemán. Exactamente son los jinetes (Reiter en alemán significa jinete en español) del ominoso Hans que es una abreviatura del nombre alemán Johannes (Juan). Así que los adeptos de Hans Reiter en realidad son Hans' Reiter o sea los Cuatro Jinetes (Reiter) anunciados por San Juan (Hans) y anteceden al apocalipsis humano. Los críticos son tan distintos entre sí como los jinetes. Todos vienen de países diferentes y llevan diferentes armas, en su caso verbales e intelectuales, y la depresión de Morini causada por sus deficiencias corporales aunado a su estado de salud que cada vez es más decadente, inclusive parece imposible que no termine nunca de morir, estos hechos le otorgarían el papel del cuarto jinete que es el más tenue, casi transparente. Incluso el apellido Morini se asemeja al verbo italiano moriré, esto sostiene la idea que Morini representa el cuarto jinete.

En el primer capítulo los tres primeros introducen la violencia irracional, como ya antes se mencionó, cuando casi matan al taxista, un acto disruptivo que podría compararse al suceso donde son tocadas las trompetas de los jinetes apocalípticos. Después los casos de violencia aumentan tanto en cantidad como en intensidad. El nombre Hans Reiter no es solo un nombre parlante, el nombre 
cifra el destino: "El nombre brilla como la luna. El nombre, con su cuerno, abre un camino en el sueño y el hombre camina por ese sendero. Un sendero tembloroso. Siempre crudo. El sendero de Ilegada o salida del infierno" (Bolaño, 2010, p. 294). El nombre es el sendero y ahí está cifrado el destino. Además realmente existieron por lo menos dos alemanes nazis que ostentaron el nombre de Hans Reiter en el Tercer Reich. Uno fue un doctor (Halter, 2000, p. 302) y el otro un lugarteniente de la SS. En sus investigaciones sobre una enfermedad que hasta hoy se llama Morbus Reiter, el doctor estuvo profundamente involucrado en experimentos inhumanos en un campo de concentración. Aunque Hans Reiter no es el único personaje en la novela que lleva un nombre parlante, si es el que dormita agazapado en las vértebras de la trama.

Queda claro que las alusiones apocalípticas de 2666 no se pueden interpretar como un aviso directo para ejercer la religión cristiana en exceso, sino que se lee como una parábola para creer en la posibilidad de un cambio radical en dirección a la justicia dentro de un sistema totalmente podrido. Hoy en día el término apocalipsis ya no se refiere tanto o solo a su sentido religioso que prevé después de la destrucción del mundo una corte y el juicio de las naciones seguido por la nueva Jerusalén Celestial. En vez de la escatología universal que espera que una entidad intervenga desde fuera, nuestra sociedad tiene que independizarse del mal y encontrar justicia dentro de sí misma para impedir que todo lo que tiene principio sea aniquilado cuando lleguemos al año 2666.

Volviendo a la pregunta que planteamos al principio, ahora podemos especificar: La estética del mal que plantea Bolaño en 2666 es más bien una estética del apocalipsis. ¿Pero en qué consiste la promesa de salvación (Heilsversprechen) que encontramos en la narración bolaniana? ¿Cuál es la solución que según Baudrillard, el apocalipsis es en sí? (2006, p. 142)

\section{El apocatarsis como Heilsversprechen del siglo XXI}

"Bienaventurado el que lee, y los que oyen las palabras de esta profecía, y guardan las cosas en ellas escritas; porque el tiempo está cerca" (Ap. 1:3, Reina-Valera, 1960). El apocalipsis de San Juan es el último capítulo del nuevo testamento y cuenta la revelación del fin del mundo causado por la pérdida de amor del pueblo. Después de la derrota de la sociedad, Dios baja personalmente al mundo. Antes 
pone a prueba todos sus seguidores, para ver quienes realmente creen en la llegada del reino de los cielos.

La violencia recurrente parece formar parte de cada capítulo de la novela y la sociedad está condenada en un letargo paralizante causado por la resignación. Los sistemas que fueron formados dentro de las sociedades diferentes, superaron a la capacidad humana de controlarlos. El miedo del poder en la gente construyó un monstruo burocrático y corrupto que es más inteligente que sus creadores originales. Mientras el mundo entero parece desplomarse y todo el mundo solo mira sin reaccionar, en un nivel superior se desarrolla una salida. El fin del mundo no está descrito directamente dentro de la novela, pero la candente amenaza de derrota moral sigue flotando sobre cada relato.

Las alusiones apocalípticas atemorizan, pero al mismo tiempo contienen la esperanza del reino de Dios después de la purificación del mundo de todos los males. Si cada presencia humana contiene al mismo tiempo lo bueno y lo malo como lo explica Baudrillard, es una consecuencia lógica que al formarse una abundancia o un desplome, vendrá la escalada que destruye a ambos. Igual que la tragedia antigua, el texto narrativo puede evocar una catarsis aristotélica cuando los lectores son confrontados con la compasión y el miedo (griego eleos y phobos) de la novela y su propia alma se purifica de estas pasiones. La única diferencia es que la purificación de la narrativa de 2666 llega al final y no en el proceso de leer.

Como la estética de Bolaño no cabe cien por ciento en la teoría aristotélica de la catarsis, ni en el género del apocalipsis, introduciremos el término apocatarsis para explicar el fenómeno bolaniano. Y describir el momento purificador dentro de la narrativa bolaniana. Este término obsoleto que ahora solo se usa en situaciones relacionadas con la medicina y describe el procedimiento de limpiar algo de todo. El prefijo griego apo- significa aparte o fuera y en combinación con la catarsis (purificación, limpieza) tenemos el significado requerido para describir la purificación final por compasión aristotélica y miedo apocalíptico. La semejanza lingüística entre apocalipsis y apocatarsis respalda el significado. 
La apocatarsis de 2666 se realiza mediante la combinación de la atmósfera amenazante dentro de la novela y la omnipresente expectación de la derrota social en combinación con la certeza de la llegada de la gracia divina. Concordamos que la esperanza del apocalipsis discursivo es provocada por alusiones apocalípticas y la catarsis del alma en el sentido aristotélico. Roberto Bolaño completa la apocatarsis con comentarios sobre el rol de la literatura tanto en el destino individual como en lo social.

El autor comprometido estimula la esperanza del lector que ahora realiza parte de su responsabilidad de prepararse para un mundo mejor al que llegaremos cuando los sistemas actuales desaparezcan. Por la recurrente autoreferencia al acto creativo literario se aumentan, tanto la responsabilidad del lector, como la del autor. En diferentes ocasiones son los personajes secundarios, como el señor Seaman, quienes hacen las referencias. En el nivel del discurso narrativo se endereza la recepción de los lectores, o sea, las palabras servían para ese fin:

Leer es como pensar, como rezar, como hablar con un amigo, como exponer tus ideas, como escuchar las ideas de los otros [...] Pero sobre todo leí un libro que leí en uno de los momentos más desesperados de mi vida y que me devolvió la serenidad. ¿Qué libro es ése? ¿Qué libro es ése?. (Bolaño, 2004, p. 326)".

No solo encontramos la literatura como tema directo como en el caso del escritor Archimboldi o los críticos de literatura, sino existen menciones como la de Seaman o la siguiente que enfatiza el rol de la literatura. El escritor ruso, Ivánov que fue asesinado por el estado antes dijo abiertamente que tanto el literato como el arte deben dar voz a las personas subalternas dentro de la sociedad (Bolaño, 2004).

Aunque por un lado la complejidad de 2666 cierre la novela con los siete sellos, por el otro lado permite al lector atento entender paulatinamente, que el mundo parece estar siendo derrotado, pero que va a seguir a pesar de las diversas representaciones del mal que ahora mismo pueblan nuestro mundo. No se ha de comparar la apocatarsis como exigencia de indignación con la apocastasis cristiana, porque esa incluye a los incrédulos del Heilsversprechen. Sería más bien una 
continuación del letargo como esperanza de que Dios lo resuelva todo. La narración comprometida exige indignación. En la confrontación directa con la omnipresencia del mal en el mundo, el escritor comprometido provoca la purificación moral del recipiente. La apocatarsis es un cambio apocalíptico dentro de la conciencia de la sociedad.

La conclusión final de la novela 2666 de Roberto Bolaño (2004) será la siguiente: para no abrumarnos y perdernos dentro del mal excesivo que nos rodea, los literatos tenemos la gran responsabilidad de indignarnos y a su vez purificar el alma colectiva de nuestra sociedad.

\section{Referencias}

Arendt, H. (2011): Eichmann in Jerusalem. Ein Bericht von der Banalität des

Bösen. München: Piper.

Baudrillard, J. (2006): Die Intelligenz des Bösen. Wien: Passagen.

Bernabéu Albert, S., Mena García, C. (2012): El feminicidio de Ciudad Juárez. Repercusiones legales y culturales de la impunidad. Sevilla: Universidad Internacional de Andalucía.

Bolaño, R. (1999): Amuleto. Barcelona: Anagrama.

Bolaño, R. (2004): 2666. Barcelona: Anagrama.

Bolaño, R. (2010): Cuentos. Barcelona: Anagrama.

Ediciones Rialp (1981): Gran enciclopedia RIALP. Madrid: Ediciones Rialp.

Goethe, Johann Wolfgang von (2000): Faust. Der Tragödie erster Teil Stuttgart: Reclam.

Halter, H. (2000): Arzt und Agitator, Der Spiegel (11), 302-303.

Kant, Immanuel (1792): Ueber das radikale Böse in der menschlichen Natur. [s.I.]: [s.n.].

Rojas Toro, F., López de Abiada, J. M. (2012): La ciudad y el motivo del homo sacer. Acercamiento a 2666, de Roberto Bolaño, en: El feminicidio de ciudad Juárez. Repercusiones legales y culturales de la impunidad. Universidad Internacional de Andalucía: Sevilla, 183-198.

Stajnfeld, S. (2012): Cuatro imágenes del mal en 2666 de Roberto Bolaño, Fuentes Humanísticas, $24(44), 69-82$. 
Suerbaum, U. (1985): Intertextualität und Gattung: Beispielreihen und Hypothesen, Broich/Pfister: Intertextualität: Formen, Funktionen, anglistische Fallstudien. Tübingen: Max Niemeyer, 58-77.

Valera, R. (1960): La santa biblia. Corea: Sociedades Bíblicas en América Latina.

Vargas Llosa, M. (1997): Los vasos comunicantes, en: Cartas a un joven novelista. México/D.F.: Planeta Mexicana.

Willem, B. (2013): Las palabras servían para ese fin: la literatura y el mal en 2666 de Roberto Bolaño, en: $B H S$ 90, 79-91. 